\title{
CINeGEO
}

International Journal of Environment and Geoinformatics (IJEGEO) is an international, multidisciplinary, peer reviewed, open access journal.

\section{Thermodynamic and Kinetic Desorption Analysis on Direct Air Capture of CO2 Gas Using Moisture Swing Sorbent}

\author{
Akash TALAPATRA
}

\author{
Chief in Editor
}

Prof. Dr. Cem Gazioğlu

\section{Co-Editor}

Prof. Dr. Dursun Zafer Şeker, Prof. Dr. Şinasi Kaya, Prof. Dr. Ayşegül Tanık and Assist. Prof. Dr. Volkan Demir

\section{Editorial Committee (2019)}

\begin{abstract}
Assos. Prof. Dr. Abdullah Aksu (TR), Prof. Dr. Bedri Alpar (TR), Prof. Dr. Lale Balas (TR), Prof. Dr. Levent Bat (TR), Prof. Dr. Paul Bates (UK), Prof. Dr. Bülent Bayram (TR), Prof. Dr. Luis M. Botana (ES), Prof. Dr. Nuray Çağlar (TR), Prof. Dr. Sukanta Dash (IN), Dr. Soofia T. Elias (UK), Prof. Dr. A. Evren Erginal (TR), Assoc. Prof. Dr. Cüneyt Erenoğlu (TR), Dr. Dieter Fritsch (DE), Assos. Prof. Dr. Çiğdem Göksel (TR), Prof.Dr. Lena Halounova (CZ), Prof. Dr. Manik Kalubarme (IN), Dr. Hakan Kaya (TR), Assist. Prof. Dr. Serkan Kükrer (TR), Assoc. Prof. Dr. Maged Marghany (MY), Prof. Dr. Michael Meadows (ZA), Prof. Dr. Nebiye Musaoğlu (TR), Prof. Dr. Erhan Mutlu (TR), Prof. Dr. Masafumi Nakagawa (JP), Prof. Dr. Hasan Özdemir (TR), Prof. Dr. Chryssy Potsiou (GR), Prof. Dr. Erol Sar1 (TR), Prof. Dr. Maria Paradiso (IT), Prof. Dr. Petros Patias (GR), Prof. Dr. Elif Sertel (TR), Prof. Dr. Nüket Sivri (TR), Assoc. Prof. Dr. Füsun Balık Şanlı (TR), Prof. Dr. Uğur Şanlı (TR), Assoc. Prof. Dr. Oral Yağcı (US), Prof. Dr. Seyfettin Taş (TR), Assoc. Prof. Dr. Ömer Suat Taşkın (TR), Dr. İnese Varna (LV), Dr. Petra Visser (NL), Prof. Dr. Selma Ünlü (TR), Assoc. Prof. Dr. İ. Noyan Yılmaz (AU), Prof. Dr. Murat Yakar (TR), Assit. Prof. Dr. Sibel Zeki (TR)
\end{abstract}

\footnotetext{
Abstracting and Indexing: DOAJ, Index Copernicus, OAJI, Scientific Indexing Services, Journal Factor, Google Scholar,
} Ulrich's Periodicals Directory, WorldCat, DRJI, ResearchBib, SOBIAD 


\title{
Thermodynamic and Kinetic Desorption Analysis on Direct Air Capture of CO2 Gas Using Moisture Swing Sorbent
}

\author{
Akash Talapatra \\ Department of Petroleum and Mining Engineering, Cuet, Chittagong, BANGLADESH \\ * Corresponding author: Name Surname \\ E-mail: talapatraakash@gmail.com
}

Received 14 Feb 2019

Accepted 22 May 2019

How to cite: Talapatra (2018). Thermodynamic and Kinetic Desorption Analysis on Direct Air Capture of CO2 Gas Using Moisture Swing Sorbent, International Journal of Environment and Geoinformatics (IJEGEO), 6(2), 186-191. DOI: 10.30897/ijegeo.526921

\begin{abstract}
An anion exchangeable resin sorbent originated from amine was used to capture and absorb $\mathrm{CO} 2$ from atmospheric air. The sorbent is capable to absorb $\mathrm{CO} 2$ gas in dry location, though it releases $\mathrm{CO} 2$ gas when it is exposed to water vapor or liquid water. The isotherm test on absorption provides the evidence that the sorbent can act effectively at the very low concentration of $\mathrm{CO} 2$. Its capacity of absorption in the form of carbonate ion is $0.86 \mathrm{~mol} / \mathrm{kg}$, which is identical to nearing of 21 litter of CO2 gas under $100 \mathrm{kPa}$ and $25^{\circ} \mathrm{C}$. Langmuir equation detailed the absorption isotherm better at higher saturation. The kinetic desorption of $\mathrm{CO} 2 \mathrm{spread}$ over in a flat polypropylene sheet has been practiced by the well-developed models and experiments. After that, the desorption coefficient, kinetic desorption parameters and stimulated energy are estimated with that equation and model. Finally more experiments should be developed to find out the exact reaction mechanism on this method with accumulating new information.
\end{abstract}

Keywords: Carbon Capture; Moisture Swing; Kinetic Desorption; Thermodynamics.

\section{Introduction}

Global warming has become one of the most important issues as the average temperature of the surface on the earth has been increased at a rate of approximate temperature of $0.072^{\circ} \mathrm{C}\left(0.13^{\circ} \mathrm{F}\right)$ per decade since the begun of 20th century (Climate Change, 2011). But this issue has been become more serious problem in the recent decades as global warming is already at the stage of out of control. It has been observed that the rate of carbon emission has been increased nearly twice nowadays from the past years (from year 1905s to year 2005s) (Climate change, 2007; Key world En. Sta., 2010; Ülker, et al., 2018). According to the statement of IPCC's A1F1 circumstance, it is predicted that the global surface temperature would increase nearly $4^{\circ} \mathrm{C}$ by the end of 21st century, if the rate of fossil fuels consumption yet dominates the field of total fuel or energy consumption all over the world. In recent decades, more than $80 \%$ of the total energy consumption and approximately $90 \%$ emission of $\mathrm{CO} 2$ have come from burning of fossil fuels (Keith et al., 2005).

Carbon capture and storage (CCS) technologies have mainly focused on the capturing of emitted $\mathrm{CO} 2$ from the large concentrated sources e.g. power plants, fertilizer plants etc. According to the estimation of IPPC, the industrial and power sectors are mostly responsible for nearly $60 \%$ of total carbon dioxide emissions and the CCS technologies can reduce about $50 \%$ of these global emissions by the end of year 2050s. A report evaluated by IEA (2011) shows that approximately $24 \mathrm{Gt}$ of CO2 was emitted in 2010, where $12 \mathrm{Gt}$ of that emitted CO2 gas added to the atmospheric air that might cause the increase of the $\mathrm{CO} 2$ concentration in the atmosphere by 1.3ppm (IPCC, 2005; URL 1 and 2, 2011). So, capturing the $\mathrm{CO} 2$ gas emits from the largest intensive stationary sources would be the exact solution to mitigate the greenhouse effect on the atmosphere.

Direct capture of $\mathrm{CO} 2$ gas from the atmospheric air was first put forward for consideration by a Lackner et al. (1999). The feasibility and economic viability of the carbon capture technology depend on the cost analysis and energy requirement for the process. The technology should be implied mostly in the sectors that produce $\mathrm{CO} 2$ gas from fossil fuel burning and consumption. Then that captured $\mathrm{CO} 2$ gas can be synthesized greatly and efficiently to produce 'synfuel' to reuse the carbon as a recycled energy fuel (Socolow, et al., 2011; Lackner, 2009).

However, Klaus Lackner introduces an air capture technology that uses an ion-exchange resin material associated with moisture sorbent based on the cycle of absorption-desorption process (Lackner, 2009). Here, the ion-exchange resin material is combined with moisture swing sorbent to increase the capture capability. The moisture sorbent would be able to capture and absorb $\mathrm{CO} 2$ gas from atmospheric air when the process will be held under dry circumstance, but the releasing of the absorbed $\mathrm{CO} 2$ may be held under the higher expose of humidity (Zeman, 2009). For this process, the required amount of energy may be needed approximately $50 \mathrm{KJ} / \mathrm{mol}$ of $\mathrm{CO} 2$. The liquid hydrocarbon fuel may contain densities nearly $45-50 \mathrm{MJ} / \mathrm{Kg}$ where they release about $3 \mathrm{Kg}$ of $\mathrm{CO} 2$ to the air after the fuels get combusted. Approximately $3.5 \mathrm{MJ}$ of heat energy may be 
needed to mitigate this amount of $\mathrm{CO} 2$ from the ambient air. If this is assumed that the conversion efficiency of fuel to electricity is about $50 \%$, then $16 \%$ of electric energy would perform to capture the emitted $\mathrm{CO} 2$ (Lackner, 2009).

This experiment has shown the performances of resin based material as sorbent at the time of a moisture swing operation. A possible type of absorption mechanism should be applied to signify the behaviour of the $\mathrm{CO} 2$ absorption during the moisture swing cycle by arranging a sequence of isothermal equilibrium tests. However, some data of kinetic desorption are available. So, some tests of the kinetic desorption are accomplished to explore the regeneration step. For that, various subsisted models would be initiated to describe the nature of desorption phase. Not only that, but also some segments of the report would ascribe to the water adhesion along with resin beads and sheet.

\section{Experimental Methods:}

\section{Material Preparation}

The resin sheet employed for the experiments was incision into a noodle's shape and preheated in 85o90 oC DI water for few times. After that the noodle shape material was preheated to make the shape with $2 \mathrm{~mm}$ wide, $30 \mathrm{~cm}$ long and $1 \mathrm{~mm}$ thick.

A solution of $1 \mathrm{M} \mathrm{Na} 2 \mathrm{CO} 3$ was added with the resin sample in dry condition to wash it twice in bicarbonate form. Then the specimen was again added with the DI water to wash the specimen for removing the residue of $\mathrm{Na} 2 \mathrm{CO} 3$ solution.

\section{Absorption Equilibrium Measurement:}

The resin specimen was installed in a specimen chamber in where the specimen was exposed to the air with no flow of $\mathrm{CO} 2$. This was held to dry the specimen without weighting it. During the time of pump working, the process was then shut down. After that, a fixed amount of $\mathrm{CO} 2$ gas was put in the specimen chamber by using a syringe and then the injected gas forced to cycle for 12 hours so that it could allow the system to move at the equilibrium condition. At that time, the amount of humidity was measured fixed at 5ppt, which means that the relative humidity was then referred approximately $10 \%$ when the atmospheric temperature was in $32^{\circ} \mathrm{C}$. It is also to be noted that this process was held under dry location at average weather condition.

Here, the total volume of the entire system was $1.25 \mathrm{~L}$ as the concentration of $\mathrm{CO} 2$ grown to $400 \mathrm{ppm}$ after $0.5 \mathrm{~mL}$ of it was injected each time. During the equilibrium condition, the amount of absorbed $\mathrm{CO} 2$ can be estimated by:

$$
q_{e}=\frac{P_{a t m} \times V_{i n j}}{R T_{a m b}}-\frac{P V_{o} C}{R T}
$$

Where,

Patm $=$ the ambient pressure.

Vinj = total quantity of injected $\mathrm{CO} 2$.

$\mathrm{R}=$ universal constant of gas.
$\mathrm{Tamb}=$ the ambient temperature.

$\mathrm{T}=$ temperature of the system.

$\mathrm{P}=$ pressure of the system.

$\mathrm{Vo}=$ volume of the system.

$\mathrm{C}=$ balance concentration of $\mathrm{CO} 2$ calculated by IRGA (Infrared Gas Analyzer).

After considering the average pressure within the outside and inside of the system, equation (1) can be more simplified to the following term:

$$
q_{e}=\left(\frac{V_{i n j}}{T_{a m b}}-\frac{V_{o} C}{T}\right)
$$

\section{Desorption Kinetic Study}

With a presumption, it is considered that the diffusion of liquid water and $\mathrm{CO} 2$ inward of the system is quiet rapid and the rate of the reaction will govern the phase of desorption. But this hypothesis might not to be proved within the experiment. However, this approach is only processed to expedite the conception, justify the modelization and implication. The Fig. 1 drawn below has represented the experimental system.

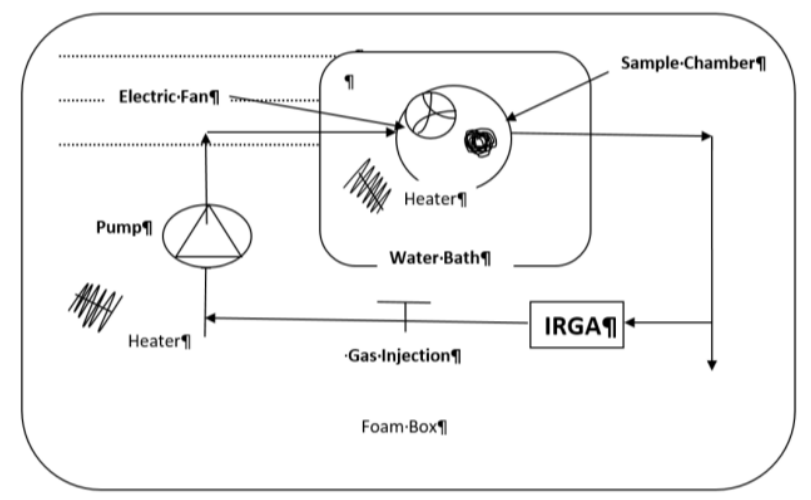

Figure 1: A diagram of the experimental study of desorption kinetic system.

During the process, the noodle's shape resin sample was disclosed to dry air for one day, of which the concentrations of $\mathrm{CO} 2$ and water were approximately $440 \mathrm{ppm}$ and $0.7 \mathrm{ppt}$ respectively. One more thing that the saturation of sorbent was assume unique $(\theta=1)$ and the sample in bicarbonate form was fully weighted after the pretreatment occurred.

All the apparatus associated with the chamber and tubes, were installed in a foam case that had lower level of temperature than the water bath had. This condition was worked to eliminate the condensation level inside the system effectively. Thus, it was confirmed that the description phase had the relative humidity of $100 \%$. An electric fan placed in the sample the sample chamber that was able to create $4 \mathrm{~m} / \mathrm{s}$ of wind velocity. This fan was highly enough to go beyond the boundary layer effect.

This should be noted that the concentration of $\mathrm{CO} 2$ was impeded by the IRGA in each time. Now, at an instantaneous time $t n$, the quantity of releasing $\mathrm{CO} 2$ can be estimated by:

$$
q_{d}=\frac{P V_{O} C}{R T}-\frac{P_{O} V_{O} C_{O}}{R T}
$$


Where, $\mathrm{P}_{\mathrm{O}}=$ initial pressure of the system.

$\mathrm{C}_{\mathrm{O}}=$ initial concentration of the system.

Assuming the pressure a constant term, equation (3) becomes:

$$
q_{d}=\frac{P_{O} V_{O}}{R T}\left(C-C_{O}\right)
$$

Then, the sample's saturation can be determined by:

$$
\theta=1-\frac{q_{d}}{q_{\infty}}
$$

Where,

$\mathrm{q}_{\infty}=$ the capacity of the sample.

This can be measured by determining the capacity of sorbent $(1 \mathrm{~kg})$ and the mass of sample, $m$. The perceptible rate of desorption is defined by a term, $\mathrm{d} \theta / \mathrm{dt}$. This term can be estimated in numerical process by deriving the curve of $\theta$ with respect to the time.

\section{Experimental Results and Discussion:}

\section{Absorption Isotherm:}

For a sorbent of $\mathrm{CO} 2$, the saturation of it at the circumstance of equilibrium is expressed by qe/q $\infty$, in where the symbol qe is defined as the quantity of $\mathrm{CO} 2$ that the sorbent can absorb when the condition reaches at the equilibrium point and another symbol q $\infty$ is defined as the capacity of the sorbent.

The transformation of classic Langmuir equation may be written as:

$$
\frac{1}{q_{e}}=\frac{1}{K_{a} q_{\infty}} \frac{1}{P_{e}}+\frac{1}{q_{\infty}}
$$

Here, the function 1/qe may be linear with the other function of $1 / \mathrm{Pe}$, if the act of conducting of the sorbent is followed by Langmuir's model.

By plotting a curve of $1 / \mathrm{q}_{\mathrm{e}}$ versus $1 / \mathrm{P}_{\mathrm{e}}$, a linear relationship is acquired along with a correlation coefficient value of 0.99 . After that, the capacity and equilibrium constant of the absorbed $\mathrm{CO} 2, \mathrm{~K}_{\mathrm{a}}$ is calculated from the slope and intercept of curve. If the mass of the selected resin sample can be determined, then the absorption capacity of $\mathrm{CO} 2$ of $1 \mathrm{~kg}$ resin may be calculated. Actually the mass of the selected resin sample is varied notably under several conditions, as the resin sheet is significantly sensitive to the moisture and liquid water used in the experiment. Incidentally, it should be mentioned that the reference measurement is chosen arbitrarily from the mass of the resin sample when it must expose in dry air for 12 hours at the concentrations of $\mathrm{CO} 2$ and water nearly by $440 \mathrm{ppm}$ and $0.7 \mathrm{ppt}$ respectively.

Table 1: Absorption representation at $25^{\circ} \mathrm{C}$

\begin{tabular}{lll}
$\mathbf{0}(\mathrm{mol} \mathrm{CO} / \mathrm{kg})$ & $\mathrm{K}_{\mathrm{a}}\left(1 / \mathrm{P}_{\mathrm{a}}\right)$ & Correlation Coefficient \\
\hline
\end{tabular}

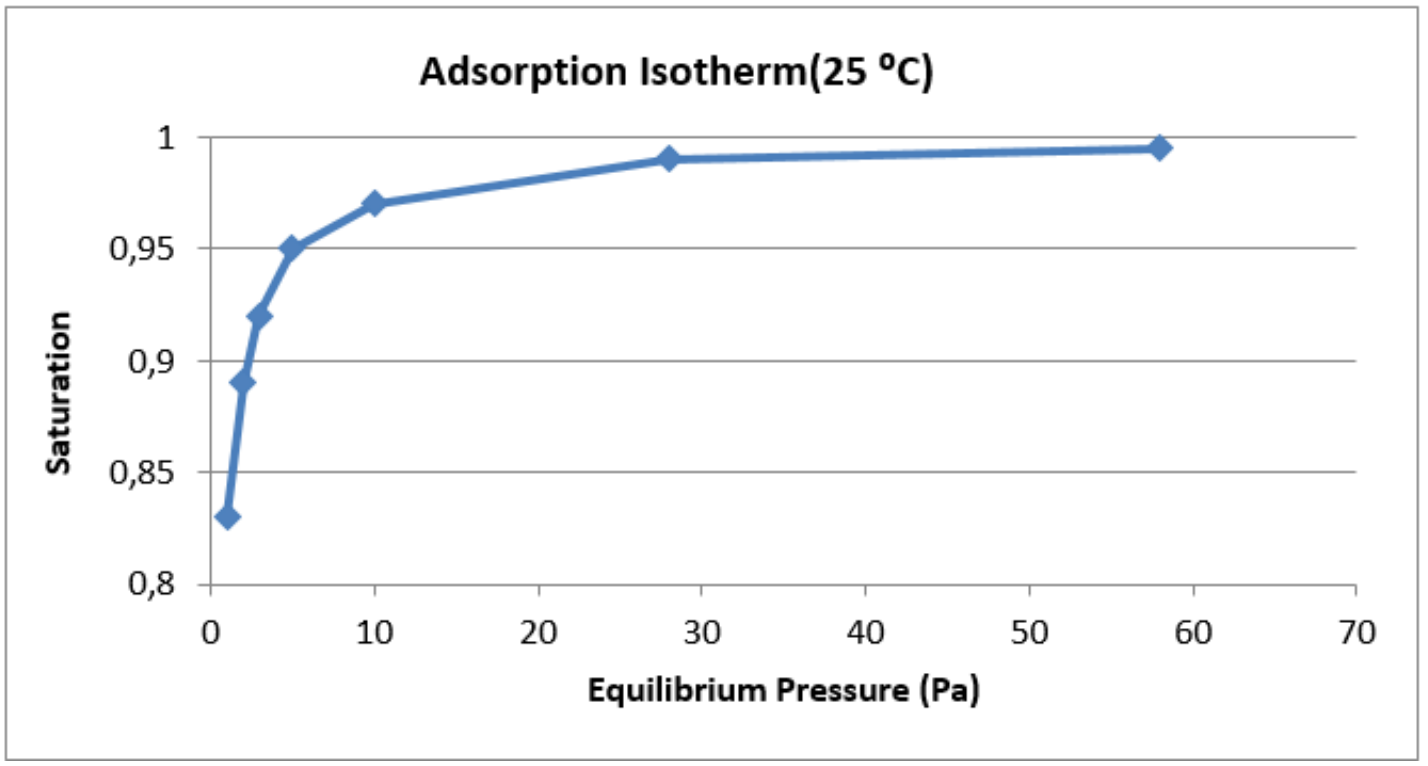

Figure 2: Absorption isotherm plotted by Langmuir model.

It has been shown clearly in Fig. 2 that at high saturation, the absorption isotherm can be described well by Langmuir model. Here, the data are found in limited range is very near to the fully saturation point $(\theta=1)$, as the concentration of $\mathrm{CO} 2$ is obtained without any certainty below the value of $10 \mathrm{ppm}$. The Table 1 gives the summarization of $\mathrm{CO} 2$ capacity and equilibrium constant that are measured from the curve of Langmuir equation. As initiated from the carbonate shape with $1 \mathrm{~kg}$ of material, the $\mathrm{CO} 2$ absorption is associated with some functional groups of $1.72 \mathrm{~mol}$ of the exchangeable ion. This result is differentiated from previous examined 
results done by Wang et al. (2011) (1.78 for the hydroxide form and $1.9 \mathrm{~mol} / \mathrm{kg}$ of anion density of material for carbonate form). Though there is an existed range of experimental error, still the functional groups have huge potentiality to absorb a large amount of $\mathrm{CO} 2$.

The equilibrium constant provided from the curve by Langmuir model is essential to portend the function of material at equilibrium positions. The curve further exhibits that the very high saturation of sorbent over 0.99 is found when the concentration of ambient $\mathrm{CO} 2$ remains at 5.0ppt. Not only that, but also the sorbent is highly capable to attain high saturation over 0.95 , if there remains low concentration of $\mathrm{CO} 2$ of $50 \mathrm{ppm}$ at $5 \mathrm{~Pa}$. This indicates that $\mathrm{CO} 2$ from atmospheric air is bounded strongly enough by the anion exchange resin of quaternary ammonia.

\section{Desorption Kinetic Study}

The same sample was exercised for this desorption kinetic study that was previously used for measurement of the absorption isotherm study. So, its capacity measured before was, $\mathrm{q} \infty=7.00 \times 10-4 \mathrm{~mol}$.

When the sorbent simply initiated for liberating, then the rate of desorption can be estimated by deriving saturation curve of $\theta$ versus time in numerically. Former investigations display that the performance of sorbent at equilibrium condition can be interpreted significantly by Langmuir equation using some parameters of higher correlation. Still we imply this model to explore out the performance of sorbent in kinetic way in desorption phase. The rate of reaction at this phase can be expressed by the equation written in below:

$$
\frac{d \theta}{d t}=K_{a}(1-\theta) P-K_{a} \theta
$$

Where, the two terms express the absorption rate and desorption rate respectively. It is considered that the second term governs the reaction rate at the starting of desorption phase. In this manner, the equation (7) would be more simplified into the following form:

$$
\frac{d \theta}{d t}=-K_{d} \theta
$$

The solution of the above mentioned homogenous differential equation of first order can be expressed resolved simply by the given form:

Where,

$$
\theta=A e^{-K_{d} t}
$$

$\mathrm{A}=\mathrm{a}$ constant obtained from boundary condition.

The performance of sample may be noted at the very executing times when it was entirely saturated to begin the releasing of $\mathrm{CO} 2$. The reason behind this case was to take almost 10 seconds to complete the initial operations by the sample, such as before initiating the logging of right data, conduction of the resin into the chamber and switching on the electric fan. Now the constant $\mathrm{A}$ is remained and transfigured into the equation (10) as:

$$
\ln \theta=-K_{d} t+\ln A
$$

By plotting the graph of $\ln \theta$ versus time from three various temperatures, straight lines can be found from the first minute of desorption phase with meeting the desired correlation coefficients. Then, the obtained slopes from the straight lines are used for determining the desorption constant, $\mathrm{K}_{\mathrm{d}}$. The obtained results are charted out in Table 2.

Table 2: Values of desorption constant under three various temperatures

\begin{tabular}{|lll|}
\hline $\mathbf{2 5}$ & $\mathrm{K}_{\mathrm{d}}\left(\times 10^{-3} \mathrm{~s}^{-1}\right)$ & Correlation coefficient \\
\hline $\mathbf{3 5}$ & 0.71 & 0.97 \\
\hline $\mathbf{4 6}$ & 1.45 & 0.98 \\
\hline Table 3: Values of desorption kinetic parameters & 0.99 \\
\hline $\mathrm{K}_{0}$ & 2.27 & \\
$\mathbf{2 . 5 5} \times \mathbf{1 0}^{\mathbf{5}}$ & $\mathrm{E}_{\mathrm{a}}(\mathrm{KJ} / \mathrm{mol})$ & Correlation coefficient \\
\hline
\end{tabular}

It is shown from the Table 2 that the increasing temperature can efficiently indulge the rate of desorption. Following the Arrhenius equation, the desorption rate constants resulted from the three various temperatures are expressed as:

$$
K_{d}=K_{O} e^{-E_{a} / R T}
$$

Where,

$$
\begin{aligned}
& \mathrm{Ea}=\text { stimulated energy of reaction. } \\
& \mathrm{KO}=\text { a factor of pre-exponential function. }
\end{aligned}
$$

Again, the transformation of Arrhenius equation can be expressed as:

$$
\ln K_{d}=\ln K_{O}-E_{a} / R T
$$

After arranging the graph of $\operatorname{lnKd}$ versus time, the value of $\mathrm{Ea}$ and $\mathrm{KO}$ are calculated from the slope and intercept. Then the values are charted out in Table 3 .

The kinetic desorption parameters are performed to support for predicting the rate constant values in a low temperature range that would be adequate for the current exercise of this material. The stimulated energy, Ea express the minimum required energy for initiating the reaction, in other words, the maximum barrier it has to overcome. The measured variation of the description enthalpy has been calculated by Wang, $\mathrm{T}$ et al. is $\Delta \mathrm{Ho}=31.80 \mathrm{KJ} / \mathrm{mol}$ (Wang et al. 2011). This value is almost fitting with the value of $\mathrm{Ea}$. The rate of desorption from the reaction can be accelerated and the 
stimulated energy can be decreased by the further development on the material itself.

In a confined system, the saturation of the sorbent, $\theta$ is related with the partial pressure of $\mathrm{CO} 2$. Then the partial $\mathrm{CO} 2$ pressure can be defined as a function of $\theta$ by the given form in below:

Where

$$
P=\frac{q_{\infty}(1-\theta) R T}{V_{O}}+C_{O} P_{O}
$$
the system.

$\mathrm{COPO}=$ initial partial pressure of $\mathrm{CO} 2$ within

This also can be transfigured into the form $\frac{n_{O} R T}{V_{O}}$,

Where, no= preliminary number of $\mathrm{CO} 2$ moles into the chamber.

Then, again the equation (7) can be written as:

$\frac{d \theta}{d t}=\frac{q_{\infty} R T K_{a}}{V_{O}}(1-\theta)^{2}+\left(\frac{n_{O} R T K_{a}}{V_{O}}+K_{d}\right)(1-\theta)-K_{d}$ (Eq.14)

One can gain a curve of $d \theta / d t$ versus time by deriving the empirical curve of $\theta$ versus time in numerically. Now, the value of $\mathrm{d} \theta / \mathrm{dt}$ can be measured form the equation (14), as the value of $\mathrm{Kd}$ has been calculated previously. Here, the absorption rate constant, $\mathrm{Ka}$ is the only parameter that is unknown and can be determined from the empirical curve of $\mathrm{d} \theta / \mathrm{dt}$ in a certain range. However, the calculation of the exact value of $\mathrm{Ka}$ is not so much accurate, because of the inaccurate variation of the numerical derivation. All the results of $\mathrm{Ka}$, calculated from the experimental data of Wang, $\mathrm{T}$ et al. are charted out in Table 4.

Table 4: Calculated results of $\mathrm{K}_{\mathrm{a}}$ in desorption phase

\begin{tabular}{|c|c|c|}
\hline Temperature $\left({ }^{\circ} \mathrm{C}\right)$ & $\begin{array}{l}\mathrm{K}_{\mathrm{a}} \text { from the plot of } \mathrm{d \theta} / \mathrm{dt} \\
\qquad\left(\times 10^{-6} \mathrm{~Pa}^{-1} \mathrm{~s}^{-1}\right)\end{array}$ & $\begin{array}{l}\mathrm{K}_{\mathrm{a}} \text { from Wang, } \mathrm{T} \text { et al. } \\
\qquad\left(\times 10^{-6} \mathrm{~Pa}^{-1} \mathrm{~s}^{-1}\right)\end{array}$ \\
\hline 25 & 5.4 & 2.8 \\
\hline 35 & 6.5 & 3.79 \\
\hline 46 & 9.1 & 4.21 \\
\hline
\end{tabular}

\section{Acknowledgements}

The author gratefully acknowledges the help of the one of my course coordinators. He had helped me with providing some information on this topic to write this paper.

\section{References}

Climate Change Indicators in the United States. (2011). US. Environmental Protection Agency.

Climate Change. (2007). Synthesis Report; Intergovernmental Panel on Climate Change: Geneva, Switzerland. IEA (2010) Key World Energy Statistics. the order of value is static at $10^{-6} \mathrm{~Pa}^{-1}$. More experiments are anticipated to express further knowledge about the performance of the sorbent desorption phase.

\section{Conclusion}

In briefly, capturing of $\mathrm{CO} 2$ gas from the atmospheric air was employed by an amine-based exchangeable anion of resin. The sorbent is capable to release $\mathrm{CO} 2$ gas, when it is exposed to water vapor or liquid water, though it absorbs $\mathrm{CO} 2$ gas in dry condition. The isotherm test on absorption provides the evidence that the sorbent can act effectively at the very low concentration of $\mathrm{CO} 2$. Its capacity of absorption in the form of carbonate ion is $0.86 \mathrm{~mol} / \mathrm{kg}$ that is identical to nearing of 21 liter of $\mathrm{CO} 2$ under $100 \mathrm{kPa}$ and $25^{\circ} \mathrm{C}$. Langmuir equation detailed the absorption isotherm better at higher saturation.

The kinetic desorption of $\mathrm{CO} 2$ spread over in a flat polypropylene sheet has been practiced by the welldeveloped models and experiments (Stolaroff et al. 2008). That's why, the boundary layers are made thin adequate to avoid the limitations on the transport. After that, the desorption coefficient, kinetic desorption parameters and stimulated energy are estimated with that equation and model.

Finally more experiments should be developed to find out the exact reaction mechanism on this method with accumulating new information. Not only that, but also the some development on the materials would be expected.
Though it is hard to calculate the values of $\mathrm{K}_{\mathrm{a}}$ accurately,

IPCC. (2005). IPCC special report on Carbon Dioxide Capture and Storage; Prepared by working group III of the Intergovernmental Panel on Climate Change: Cambridge University Press, Cambridge, United Kingdom and NewYork,USA.

Keith, D.W., M. Ha-Duong, M., J.K. Stolaroff. (2005). Climate strategy with CO2 capture from the air. Climatic Change, 74, 17-45.

Lackner, K. S. (2009). Capture of carbon dioxide from ambient air. Eur. Phys. J. Special Topics., 176 (1), 93-1063.

Lackner, K. S., Ziock, H.-J., Grimes, P. (1999). Carbon Dioxide Extraction from Air: Is It an Option? 24th Annual Technical Conference 
on Coal Utilization and Fuel Systems, Clearwater, FL.

Lackner, K.S. (2009). Carbon of Dioxide Capture from Ambient Air. The European Physics Journal: Special Topics, 176, 93106.

Socalow, R., Desmond, M., Aines, R., Blackstock, J., Bolland, O., Kaarsberg, T., Lewis, N., Mazzotti, M., Prefer, A., Sawyer, K., Siirola, J., Smit, B., Wilcox, J. (2011). Direct Air Capture of CO2 with ChemicalsA Technology Assessment for the APS Panel on Public Affairs, 119p.

Stolaroff, J. K., Keith, D. W. and Lowry G. V. (2008). Carbon dioxide capture from atmospheric air using sodium hydroxide spray. Environ. Sci .Technol., 42(8), 27282735.

Ülker, D., Ergüven, O., Gazioğlu, C. (2018). Socio-economic impacts in a Changing Climate: Case Study Syria, International Journal of Environment and Geoinformatics (IJEGEO), Vol. 5(1), 84-93.

URL 1. http://www.iea.org (August, 2011).

URL 2. http://www.epa.gov (August, 2011).

Wang, T., Lackner, K.S., Wright, A. (2011). Moisture Swing Sorbent for Carbon Dioxide Capture from Ambient Air. Environ. Sci. Technol., 45, 66706675.

Zeman, F. (2007) .Energy and material balance of $\mathrm{CO} 2$ capture from ambient air. Environ. Sci. Technol., 41(21), 7558-7563. 